\title{
The Impact of Uterine Leiomyomas: A National Survey of Affected Women
}

\author{
Bijan J. Borah, PhD ${ }^{1}$, Wanda K. Nicholson, MD, MPH, MBA ${ }^{2}$, Linda Bradley, MD $^{3}$, and \\ Elizabeth A. Stewart, MD ${ }^{4}$ \\ ${ }^{1}$ College of Medicine and Division of Healthcare Policy \& Research, Mayo Clinic, Rochester, \\ Minnesota \\ ${ }^{2}$ Department of Obstetrics and Gynecology, Diabetes and Obesity Core, Center for Women's \\ Health Research, University of North Carolina School of Medicine, Chapel Hill, North Carolina \\ ${ }^{3}$ Department of Obstetrics and Gynecology, Cleveland Clinic, Cleveland, Ohio \\ ${ }^{4}$ School of Medicine and Division of Reproductive Endocrinology and Infertility, Department of \\ Obstetrics and Gynecology, and Department of Surgery Mayo Clinic, Rochester, Minnesota
}

\begin{abstract}
Objectives-To characterize the impact of uterine leiomyomas (fibroids) in a racially diverse sample of women in the United States.

Study Design-A total of 968 women (573 White, 268 African-American, 127 other races) aged 29-59 with self-reported symptomatic uterine leiomyomas participated in a national survey. We assessed diagnosis, information seeking, attitudes about fertility, impact on work, and treatment preferences. Frequencies and percentages were summarized. Chi-square test was used to compare age groups.
\end{abstract}

Results-Women waited an average of 3.6 years before seeking treatment for leiomyomas, and $41 \%$ saw two or more healthcare providers for diagnosis. Almost a third of employed respondents (28\%) reported missing work due to leiomyoma symptoms, and $24 \%$ felt that their symptoms prevented them from reaching their career potential. Women expressed desire for treatments that do not involve invasive surgery (79\%), preserve the uterus (51\%), and preserve fertility (43\% of women under 40).

(C) 2013 Mosby, Inc. All rights reserved.

Corresponding Author and Reprint Requests Wanda K. Nicholson, MD, MPH, MBA, Associate Professor, Obstetrics and Gynecology, Center for Women's Health Research, 3027 Old Clinic Building, CB\#7570, Chapel Hill, NC 27517, Phone (919) 843-7851, Fax (919) 966-6001, wknichol@med.unc.edu.

Publisher's Disclaimer: This is a PDF file of an unedited manuscript that has been accepted for publication. As a service to our customers we are providing this early version of the manuscript. The manuscript will undergo copyediting, typesetting, and review of the resulting proof before it is published in its final citable form. Please note that during the production process errors may be discovered which could affect the content, and all legal disclaimers that apply to the journal pertain.

Meeting Presentation

An abstract of this paper was presented at the AAGL's $41^{\text {st }}$ Global Congress of Minimally Invasive Gynecology held November 5-9, 2012 in Las Vegas, Nevada. 
Conclusions-Uterine leiomyomas cause significant morbidity. When considering treatment, women are most concerned about surgical options, especially women under 40 who want to preserve fertility.

\section{Keywords}

uterine fibroids; symptoms; hysterectomy; leiomyoma; quality of life

\section{Introduction}

Uterine leiomyomas (fibroids) are benign tumors of the uterus that affect approximately $80 \%$ of women. ${ }^{1,2}$ Most leiomyomas are asymptomatic, and most women do not undergo treatment. However, $25 \%$ of those affected have symptoms that impact activities of daily living or are severe enough to require treatment. Leiomyoma symptoms include heavy or prolonged menstrual bleeding, menstrual pain or cramping, passing blood clots, bloating, bowel or bladder dysfunction, and fatigue. ${ }^{2}$ Uterine leiomyomas are the leading cause of hysterectomy (also the most common treatment for this condition). ${ }^{3,4}$ Uterine leiomyomas have a three-fold increased relative risk and prevalence among African-American women. ${ }^{5}$

Few studies have attempted to gauge symptomatology of women with leiomyomas, assess the way that women obtain information about the disease, or reveal how women use this information to make treatment choices. A recently conducted international survey confined its assessment to only bleeding and pain symptomology. ${ }^{6}$ In addition to the physical symptoms, validated quality of life measures indicate that uterine leiomyomas impact women emotionally, including increased fears about their health along with additional considerations with regard to relationships, sexual function, body image, loss of control, and hopelessness. ${ }^{7}$ Further, the economic impact of this disease is probably underestimated given the limited amount of information on its impact on women's work. The purpose of this study is to provide a comprehensive assessment of the burden and impact of uterine leiomyomas in a diverse group of women. Because of the potentially higher impact of uterine leiomyomas on women of childbearing age, we attempted to quantitate the frequency and magnitude of morbidity in women under the age of 40 compared to older age groups: 40-49 and 50-59.

\section{Materials and Methods}

We conducted a cross-sectional survey of United States (U.S.) women aged 29-59 from December 1, 2011 to January 16, 2012. Our target sample was 1,000 participants. The sampling frame for the survey was Harris Poll Online (HPOL), which is an actively managed, continually monitored respondent panel owned by Harris Interactive (New York, NY). The Focused Ultrasound Foundation was not included or named in any part of the survey. No ads or links to the Foundation were included in the survey. The goal of HPOL is to provide a representative sample of the general population while identifying and reaching under-represented populations of interest. Harris Interactive uses a weighting algorithm with propensity score adjustment to minimize the nonrandom selection bias inherent in internetbased surveys. ${ }^{8,} 9$ In the present study, national representativeness of the final survey sample 
was sought to be achieved by a weighting algorithm based on age, education, region and income information based on March 2010 Current Population Survey Database. HPOL respondents are recruited from co-registration offers on partners' websites, targeted emails sent by online partners to their audiences, graphical and text banner placement on partners' websites (including social media, news, search, and community portals), trade show presentations, targeted postal mail invitations, and telephone recruitment of targeted populations. Each recruitment source is carefully vetted through a rigorous interviewing and testing process and then monitored for response quality on an ongoing basis. HPOL respondent information is actively screened and updated along numerous demographic and psychographic variables to allow for precision in the online sample. The email's subject line was "We need your opinion, please participate today!" The text said "Hello, The latest Harris Poll Online survey is now open and we want your opinion! In order to receive the reward mentioned, you will need to qualify and complete the survey. Panel participants receive points and chances in a sweepstakes for cash prizes for all survey participation. Neither the authors nor the Focused Ultrasound Foundation are involved in the HPOL reward program. Additional details about Harris' online panel are available online at (http:// www.harrisinteractive.com/MethodsTools/DataCollection/HarrisPollOnlinePanel.aspx and http://www.harrisinteractive.com/vault/HI_SP_Sheet_SamplingSupportandDesign.pdf). The Institutional Review Board (IRB) at Mayo Clinic judged the study to be exempt.

Respondents in the targeted sample pool received an email invitation describing the study in general terms. The email directed those interested to a survey website. The survey was conducted online using secure servers at Harris Interactive. Women were screened and considered eligible to participate if they spoke English, had been diagnosed with symptomatic uterine leiomyomas, had not had a hysterectomy, and were not pregnant.

To identify women with symptomatic uterine fibroids, we first asked participants if they had experienced any of the following symptoms in the past 2 years and to select all that apply: abdominal bloating and pressure/protruding abdomen/looking pregnant; passing blood clots during your menstrual period; heavy or prolonged menstrual bleeding (i.e., menstrual flow that soaks through sanitary pads or tampons every hour or consistently lasts longer than 7 days); abdominal pain/cramping/tightness; anemia; backache or leg pains; constipation; bladder symptoms (difficulty urinating, frequent urge to urinate, etc.); fatigue; menstrual pain/cramps; painful intercourse or lack of interest in sex. If a participant checked at least one of the symptoms listed above, the next question stated, "You mentioned that you experienced [insert response] in the past 2 years. Have you ever been diagnosed by a healthcare professional with any of the following? Please select all that apply. Endometriosis; Asymptomatic uterine fibroids (i.e., fibroids that are not causing you symptoms or discomfort of any kind); Symptomatic uterine fibroids (i.e., fibroids that are causing you symptoms or discomfort of any kind); None of the above.

The initial group of respondents included 370 women over the age of 50 (38\% of the total 968 eligible respondents). Therefore, the initial age range of 21-50 was adjusted to 29-59 when no women under the age of 29 successfully screened into the study. Although the older women who screened in are nearing menopause (and probable relief from symptoms 
of leiomyoma), they provided a valuable source for comparison of quality of life issues with women under the age of 40 .

\section{Survey Instrument}

The survey consisted of twelve screening questions, eight demographic questions, and twenty-four questions concerning diagnosis and symptoms, coping with symptoms, information seeking, fertility, and concerns about treatment. The average time to complete the survey was 20 minutes.

Most survey questions were based on a 4- or 5-point Likert scale. For ease of presentation, responses were combined into a smaller number of categories. For example, symptom results reported as severe are a combination of the "severe" and "very severe" Likert points. Those reported as concerns include points marked "all of the time" and "most of the time;" those reported as important include the "important" and "very important" points grouped together, and "not applicable" was a choice when a statement did not apply to that respondent's experience or when the respondent neither agreed nor disagreed with a statement.

We also elicited responses on potential employment- and treatment-related concerns to which respondents could choose one of the following options: concerned, very concerned, somewhat concerned, unconcerned, very unconcerned, somewhat unconcerned, and not sure. For ease of interpretation, the first three of the choices were combined to form a "Concerned" category while the next three categories were combined to form a "Not Concerned" category.

With formal permission from the Society for Interventional Radiology Foundation (Fairfax, Virginia), we used quality of life questions from the Uterine Fibroid Symptom and Quality of Life (UFS-QOL) questionnaire, which was designed and validated as a reliable tool to measure health-related quality of life for women with leiomyomas. ${ }^{7}$

\section{Statistical Analysis}

Statistical analyses comprised of both bivariate and multivariate analyses. Bivariate analyses were performed using Chi-squared test of goodness of fit for categorical covariates, and ttest for continuous covariates.

Estimated prevalence ratios (PRs) were adjusted for potential confounding due to differences in the baseline characteristics of the sampled subjects. ${ }^{10}$ Although log-binomial models are suggested for estimating PRs, they are often difficult to fit due to well-known problems of convergence of the resulting likelihood function; therefore, we used Zou's modified Poisson regression to estimate PRs with the youngest group of patients (age 2939 ) as the referent group. ${ }^{11,12}$

A p-value of $<0.05$ was considered statistically significant. Analyses were conducted using Stata ${ }^{\circledR}$ statistical software, version 11.2 (StataCorp LP, College Station, Texas), which provides capabilities for analyzing survey data. 


\section{Results}

\section{Response Rate and Participant Characteristics}

Of the 140,231 people invited to participate in the online survey, 73,103 never clicked on the link, 34,902 suspended the survey, and 31,258 did not qualify (23,850 did not have symptomatic uterine fibroids, 5,010 were excluded because the target number of respondents in their specific racial/ethnic category had been met, 1,927 had undergone hysterectomy, 187 were out of the desired age range, 161 were not female, 106 were pregnant, breastfeeding, or did not meet menstrual cycle criteria, and 17 were not U.S. women)-leaving the 968 (3\%) who met each of the entry criteria, had symptomatic uterine fibroids and were able to complete the survey. Table 1 exhibits the characteristics of the survey respondents, sub-grouped by three age categories (29-39, 40-49, and 50-59). Sixty-four percent of participants were White, 28\% were Black (Black/African/African-American/ Afro-Caribbean), and $8 \%$ were from other racial backgrounds or of mixed racial background. Most women were parous (69\%). The percent of respondents within each age category were $25 \%, 46 \%$, and $29 \%$, respectively. The majority of respondents $(61 \%)$ were married or in a civil union. Educational backgrounds included $72 \%$ who had completed some form of higher education. Over half (66\%) of the respondents were employed full time (including self-employment). Of those employed who responded, 39\% earned in excess of $\$ 75,000$ annually, and $23 \%$ reported an annual income of under $\$ 35,000$ (Table 1).

The respondents in this survey reported having had uterine leiomyomas for a mean of 8.7 years (median 6 years) since diagnosis. Many women (42\%) saw two or more healthcare providers before being diagnosed; overall, women saw an average of 1.7 providers before diagnosis. The mean amount of time to seek treatment for all women in the survey was 3.6 years, while the median wait time for seeking treatment was 2 years (Table 1). While $25 \%$ of women sought treatment within the first year of experiencing symptoms, $32 \%$ waited more than 5 years before seeking treatment for these symptoms. 87\% reported discussing one or more treatment options with their providers (Table 1).

\section{Severity of Symptoms}

We collected data on severity of symptoms experienced in the past 3 months and reported in Table 2. Half of the women (50\%) reported that they did not consider their menstrual cycle to be "normal," with 56\% reporting that they had spotting or staining before or after their cycle. Nearly a third of women (29\%) characterized their cycles as heavy or with prolonged bleeding and had severe menstrual pain or severe cramps. Note that when potential confounding due to differences in patient characteristics was accounted for, most of the menstrual and nonmenstrual symptoms reported in Table 2 were not statistically different between the three age groups except for bladder symptoms, menstrual pain/cramps, and painful intercourse. In general, women in the intermediate age group 40-49 had lower prevalence ratios of those symptoms than those in the 29-39 age group.

\section{Perceptions of Leiomyomas and Impact on Quality of Life and Employment}

As shown in Appendix Table 1, women with leiomyomas had a number of concerns related to their uterine leiomyoma diagnosis. Most reported fears, including being afraid that their 
leiomyomas will grow (79\%), that there is something inside of them that doesn't belong there (69\%), that they would experience future health complications (63\%), that they will need a hysterectomy (55\%), that the leiomyomas would turn into cancer (54\%), or that the leiomyomas would affect their sex life (52\%). However, when adjusted for their baseline characteristics, the prevalence ratios in women in the three age groups did not differ by different concerns..

Women under 40 (29-39) were also more concerned than their older counterparts (40-49 and 50-59) about soiling clothes or bedding ( $44 \%$ vs. $35 \%$ and $22 \%$, respectively, $\mathrm{P}<0.001$ ), the negative impact on their femininity or sexuality (39\%, vs. $17 \%$ and $11 \%$, respectively, $\mathrm{P}=0.01$ ), and feeling sad, discouraged, or hopeless (36\% vs. $17 \%$ and $7 \%$, respectively, $\mathrm{P}<0.001)$. Furthermore, approximately a third of the women under $40(31 \%)$ reported that their uterine leiomyomas made them feel "not in control of life," as compared to $20 \%$ and $11 \%$ of the women $40-49$ and 50-59, respectively ( $\mathrm{P}=0.008$ ) (Table 3).

Some of these differences persisted even after accounting for potential confounding due to differences of baseline characteristics (Table 3). Specifically, as seen from the adjusted prevalence ratios, younger women (29-39) were more likely to report "feel tired or worn out a little/some of the time" or "feel self-conscious about weight gain a little/some of the time" or "UF interfered with physical activities all/most of the time" or "UF interfered with daily and social activities all/most of the time".

Our survey also found significant age differences in the way that uterine leiomyomas affect the lifestyle of respondents. Although every age group was affected, the women under 40 were more likely than women 40-49 and 50-59 to report that that their uterine leiomyomas affected their relationship with their partner (33\% vs. $19 \%$ \& $10 \% \mathrm{P}<0.001)$, affected their ability to take care of their home/children ( $22 \%$ vs. $12 \% \& 9 \%, \mathrm{P}=0.01)$, and affected their relationships with family/friends ( $21 \%$ vs. $13 \% \& 9 \%, \mathrm{P}<0.001)$ (Table 3$)$. However, when adjusted for the baseline characteristics, these differences were no longer statistically significant.

Respondents perceived that uterine leiomyomas negatively impacted their career potential and workplace environment (Appendix Table 2). We found significant differences in perceptions of the impact on career advancement for women under age 40 compared with women 40-49 and 50-59. When asked about their work-related experiences in the 3 months prior to the study, $28 \%$ of employed respondents reported that their uterine leiomyomas caused them to miss days of work, with a disproportionate impact on the women under 40 compared to older respondents (37\% among women 40 and under vs. 30\% and $16 \%$ among women $40-49$ and 50-59 respectively, $\mathrm{P}=0.002$ ); further, $26 \%$ were prevented from carrying out their normal work-related responsibilities ( $35 \%$ vs. $27 \%$ and $13 \%, \mathrm{P}<0.001$ ) and $24 \%$ were prevented from reaching their true career potential ( $32 \%$ vs. $24 \% \& 15 \%, \mathrm{P}=0.03$ ). However, following multivariate adjustment, these differences were no longer statistically significant. 


\section{Women's Preferences for Treatment}

Uterine-sparing treatment options were important to women whether or not they were considering a pregnancy (Table 4). The majority (51\%) of survey respondents felt it was important to have a leiomyoma treatment option that allowed a woman to keep her uterus, and these percentages were significantly higher in women under 40 (65\% vs. $47 \%$ each in the older categories, $\mathrm{P}=0.021$ ). Three-quarters of all participants (79\%) and $84 \%$ of those under 40 indicated that it was important to have a leiomyoma treatment option that did not involve invasive surgery. One-fifth (20\%) of all of the women surveyed thought it was important to have treatment options that preserved the ability to achieve pregnancy, but a higher percentage (43\%) of women under 40 said that it was important to have leiomyoma treatment procedures that protected the ability to have children. Sixty-five percent of women under age 40 reported that uterine preservation was important compared to $47 \%$ of women 40-49 and 50-59. However, note that when baseline characteristics of the sampled women were adjusted, these differences by age groups could not be sustained.

\section{Comment}

To our knowledge, this is the first large-scale survey of U.S. women with symptomatic uterine leiomyomas to describe perceptions of the impact of the leiomyomas on quality of life (symptoms, work, relationships, family, and sexual functioning) and concerns and preferences for treatments. This comprehensive assessment of the impact of uterine leiomyomas reveals the perspective of women from childbearing age to menopause. The study findings are particularly relevant when viewed within the framework of the burden of this condition. Uterine leiomyomas affect millions of women worldwide, and the cumulative incidence in the U.S. is $70 \%$ to $80 \%$ by age $50 .{ }^{13}$ The professional and economic impact of leiomyomas is likely underestimated. When including the costs of obstetrical outcomes related to leiomyomas, the total cost of this disease increases from $\$ 5.9$ billion to $\$ 34.4$ billion annually in the U.S. ${ }^{14}$

Our findings provide useful, early information on the distribution of symptoms across age categories for women with uterine fibroids. After adjustment for baseline characteristics, most symptoms (Table 2) were found to be similar across the age groups. These findings emphasize the effect of leiomyomas on physical functioning in women across the lifespan, and also suggest the need for further investigation of how perceptions of symptoms impact treatment seeking behaviors. Bladder symptoms, menstrual pain/cramps, and painful intercourse were less often reported in women in the intermediate age range (40-49) compared to the youngest age group (29-39). Differences in symptoms may be due, in part, to variations in hormonal levels, perceptions of pain and discomfort or the initial size and growth of uterine fibroids. ${ }^{15}$ The majority of women in our survey (66\%) were concerned about missed days from work. Prior data on loss of work productivity in women with leiomyomas have been limited; no prior studies have documented the level of perceived work impairment for women that are reported in this survey. ${ }^{16,17}$ Further research that incorporates women's perception of work productivity can inform the development of patient-centered outcomes for planning and implementing clinical trials that compare treatment options. Additionally, fatigue played a substantial role in women's perceptions of 
their health related quality of life. Further studies to develop patient-centered outcome measures for symptoms of fatigue and work productivity are necessary to fully compare the effectiveness of medical or surgical treatment options for leiomyomas.

Most women preferred non-invasive options for treatment irrespective of the desire for childbearing. A considerable number of hysterectomies occur each year in the U.S., with substantial costs for the healthcare system. ${ }^{17} \_20$ Despite the curative effect of hysterectomy for leiomyomas, the long-lasting health impact of hysterectomy of, even with ovarian conservation, is not completely understood. Prior studies suggest that removal of the uterus could result in fluctuations in hormonal mediators and iron balances that are thought to contribute to CHD, cognition, and dementia. ${ }^{21,22}$. The relative impact of patient preference and patient-provider communication about the choice of hysterectomy remains unclear. Of particular relevance is the role of shared decision-making in moving forward with hysterectomy or other non-surgical treatments.

The findings from the current study suggest that women across age categories are seeking information on alternatives to hysterectomy for a variety of reasons. Women verbalized the need for information on treatment options that are noninvasive and that enable them to have children in the future. Aside from fertility, many women expressed a clear desire to keep their uterus. This may be due to a variety of factors, including the need to avoid lost time at work for postoperative recuperation so that they can continue to support themselves and their families or concerns regarding post-hysterectomy sexual function and femininity. Women are well informed about drug therapies and hysterectomy.

This study has several limitations. The survey relied on self-report of leiomyomas, so some misdiagnosis likely occurred. While validation of self-report has not been carried out in each of the populations we surveyed, previous data for White and African-American women in the U.S. show that over $90 \%$ of women who self-report uterine leiomyomas are confirmed to have these lesions following review of the medical records. $5,23,24$ The lack of medical record confirmation also means that the size, location, and number of leiomyomas cannot be correlated with symptoms, work productivity or preferences for care. Since the study was based on an online survey, the standard limitations of this method apply. ${ }^{25,} 26$ In particular, these results need to be interpreted in the backdrop of potential selection bias because only women with internet access could respond to the survey. Economically and educationally advantaged women are more likely to have responded to the survey. Another potential limitation is recall bias. The age range of participants in the study varied widely. Some women may not have accurately reported their age at diagnosis or the time period between the beginning of their symptoms and seeking treatment. Finally, while we know the number of women who had discussed surgical interventions with their physicians, we do not have information on which surgical treatments they may have actually received, and therefore, the impact of surgical interventions on their responses to treatment preferences.

These limitations notwithstanding, our study has important clinical and policy implications. The results of this survey document the substantial effects of leiomyomas on women's job performance, quality of life, and concerns about intimate relationships across the lifespan. Our study results also document the increased severity of symptoms and impairment in 
women under age 40, especially the perceived impact on fertility and healthy childbearing. Women's voices should be heard by payers and clinicians when considering the types of treatment options that should be discussed, made available to, and reimbursed by payers.

The primary implication of our study is that the effect of uterine fibroids on women's quality of life deserves further attention. From a clinical perspective, our findings can inform the conduct of qualitative research and provide an opportunity to systematically analyze women's views and preferences for care. Such formative work can be used to develop clinical decision-making tools and to promote shared medical decision making for treatment between women and their providers. ${ }^{27}$ Trials should be of sufficient size to provide direct evidence on the effect of non-surgical and surgical treatments on patient-centered outcomes (e.g., quality of life, physical functioning) and for analyses specific to women of childbearing age. Finally, there is a critical need for studies of the direct and indirect (work productivity, loss of work time) costs of leiomyomas to better inform clinicians and third party payers.

\section{Background and Objective}

The relative risk for and prevalence of uterine leiomyoma, the leading cause of hysterectomy, are 3-fold greater among African-American women. The purpose of this study was to provide a comprehensive assessment of the burden and impact of uterine leiomyomas in a diverse group of women. Because of the potentially higher impact on women of childbearing age, we assessed the frequency and magnitude of morbidity in women under age 40 vs 40-49 and 50-59 years.

\section{Materials and Methods}

We conducted a cross-sectional survey of US women aged 29-59 from Dec. 1, 2011, through Jan. 16, 2012. Our target sample was 1000 participants.

We sought to achieve national representative within the final survey sample by applying a weighting algorithm based on age, education, region, and income using information from the March 2010 Current Population Survey Database.

\section{Results}

Of the 140,231 women invited to participate in the online survey, 968 (3\%) met entry criteria, had symptomatic uterine fibroids, and were able to complete the survey. Respondents reported having had uterine leiomyomas for a mean of 8.7 years (median, 6 years) since diagnosis. Many (42\%) had seen $\geq 2$ health care providers (average, 1.7) before diagnosis. The mean time to seek treatment was 3.6 years (median, 2 years) (Table). One fourth $(25 \%)$ had sought treatment within the first year of experiencing symptoms and $32 \%$ had waited $>5$ years. Treatment options had been discussed with providers by $87 \%$.

Most of the reported menstrual and nonmenstrual symptoms did not differ statistically among age groups. The prevalence ratios were lower among women aged $40-49$ years than 29-39 years. 
Women under 40 were more concerned than their older counterparts about soiling clothes or bedding, the negative impact on their femininity or sexuality, and feeling sad, discouraged, or hopeless. Among women under 40,31\% said uterine leiomyomas made them feel "not in control of life" vs $20 \%$ and $11 \%$ of those aged $40-49$ and $50-59$, respectively $(P=.008)$.

Uterus-sparing treatment options were important to women whether or not they were considering pregnancy. A small majority (51\%) of survey respondents, especially those under 40, desired a treatment option that allowed the uterus to be retained. Most participants (79\%) and $84 \%$ of those under 40 considered it important to have a leiomyoma treatment option that did not involve invasive surgery.

\section{Comment}

To our knowledge, this is the first large-scale survey of US women with symptomatic uterine leiomyomas to describe their perceptions of the impact on quality of life and concerns and preferences for treatment. Our findings are particularly relevant when viewed within the framework of the burden of this condition. Uterine leiomyomas affect millions of women worldwide; the cumulative US incidence is $70-80 \%$ by age 50 . Including related obstetrical outcomes increases the total US cost from $\$ 5.9$ billion to $\$ 34.4$ billion annually.

Our findings provide early information on the distribution of symptoms across age categories for women with uterine fibroids. After adjustment for baseline characteristics, most symptoms were similar across age groups. These findings emphasize the effect of leiomyomas on physical functioning across the lifespan and suggest the need for further investigation of ways in which perception of symptoms affects treatment-seeking behavior.

Bladder symptoms, menstrual pain/cramps, and painful intercourse were less often reported in women in the intermediate age range (40-49) than the youngest (29-39). Differences in symptoms may be due in part to variations in hormonal levels, perceptions of pain and discomfort, or initial fibroid size and growth.

The majority of women (66\%) were concerned about missed workdays. Prior data on loss of work productivity in women with leiomyomas have been limited; no prior studies have documented the levels of perceived work impairment for women that are reported in this survey. Further research that incorporates women's perception of work productivity could inform the development of patient-centered outcomes for planning and implementing clinical trials that compare treatment options.

Fatigue played a substantial role in women's perceptions of their health-related quality of life. Further studies to develop patient-centered outcome measures for symptoms of fatigue and work productivity are necessary to compare the effectiveness of medical or surgical treatment options for leiomyomas.

Most women preferred noninvasive options for treatment regardless of the desire for childbearing. Our findings suggest that women across age categories are seeking information on alternatives to hysterectomy for a variety of reasons. Women verbalized the 
need for information on treatment options that are noninvasive and preserve fertility. Many women expressed a clear desire to keep their uterus aside from future childbearing.

The primary implication of our study is that the effect of uterine fibroids on quality of life deserves further attention. Clinically, our findings can inform the conduct of qualitative research and provide an opportunity to systematically analyze women's views and preferences for care. Such formative work can be used to develop clinical decision-making tools and to promote shared decision making about treatment between women and their providers.

Trials should be large enough to provide direct evidence on the effects of nonsurgical and surgical treatments on patient-centered outcomes, such as quality of life and physical functioning, and to permit analyses specific to women of childbearing age. Finally, there is a critical need for studies of the direct and indirect (work productivity, loss of work time) costs of leiomyomas to better inform clinicians and third-party payers.

\section{Acknowledgments}

Survey questions from the validated Uterine Fibroid Survey and Quality of Life (UFS-QOL) questionnaire were used with permission from the Society of Interventional Radiology (SIR) Foundation (Fairfax, Virginia); the authors made the decision to use part of the UFS-QOL when designing this study and are solely responsible for the administration of the survey questionnaire. The SIR Foundation is not liable or responsible any findings, conclusions, or recommendations made by the authors of this manuscript. The authors thank Jill W. Roberts, M.S. (freelance medical writer in Lynchburg, Virginia contracted by the Focused Ultrasound Foundation) for assistance in preparing this manuscript.

\section{Financial Support Disclosures}

BJB and WKN: no disclosures. LB: consultant for Merit Medical, Ferring Pharmaceutical, and Endoceutics, Inc.; speaker's bureau for Ferring Pharmaceutical and Bayer Healthcare; royalties from Elsevier; editorial advisory board for Medscape; paid writer for WebMD. EAS: clinical trial investigator for InSightec and NIH (HD063312 and HD060503); consultant for Abbott and Gynesonics; scientific advisory board for Bayer Healthcare Foundation; royalties from UpToDate, Johns Hopkins University Press, and Massachusetts Medical Society.

\section{Source of the Work or Study}

The survey was funded by Fibroid Relief, a program of the Focused Ultrasound Foundation in Charlottesville, Virginia, and was conducted by Harris Interactive (New York, NY).

\section{Funding Disclosure from NIH}

Analysis was conducted by the investigators with support from NIH HD RC1063312 \& R01060503 (EAS \& BJB).

\section{APPENDIX}

\section{Appendix Table 1}

Women's Concerns Following the Diagnosis of Leiomyomas

\begin{tabular}{|c|c|c|c|c|c|c|c|c|c|}
\hline $\begin{array}{l}\text { Concerns regarding uterine } \\
\text { fibroids }\end{array}$ & $\begin{array}{c}\text { Overall } \\
\mathbf{n}=968 \\
(\%)\end{array}$ & $\begin{array}{c}(1) \\
29-39 \\
n=249 \\
(\%)\end{array}$ & $\begin{array}{c}(2) \\
40-49 \\
n=444 \\
(\%)\end{array}$ & $\begin{array}{c}(3) \\
\mathbf{5 0 - 5 9} \\
\mathbf{n}=275 \\
(\%)\end{array}$ & $\begin{array}{c}\mathbf{P} \\
\text { Value }\end{array}$ & $\begin{array}{l}\text { PR } \\
\text { (2) vs. } \\
\text { (1) }\end{array}$ & $\begin{array}{c}\text { P- } \\
\text { value }\end{array}$ & $\begin{array}{l}\text { PR } \\
\text { (3) vs. } \\
\text { (1) }\end{array}$ & $\begin{array}{c}\text { P- } \\
\text { value }\end{array}$ \\
\hline $\begin{array}{l}\text { I'm afraid that the fibroids } \\
\text { will grow }\end{array}$ & & & & & $<0.001$ & & & & \\
\hline Strongly/Somewhat agree & $763(79)$ & $217(87)$ & $376(85)$ & $170(62)$ & & 1.05 & 0.422 & 0.92 & 0.463 \\
\hline
\end{tabular}




\begin{tabular}{|c|c|c|c|c|c|c|c|c|c|}
\hline $\begin{array}{l}\text { Concerns regarding uterine } \\
\text { fibroids }\end{array}$ & $\begin{array}{c}\text { Overall } \\
\text { n=968 } \\
(\%)\end{array}$ & $\begin{array}{c}(1) \\
29-39 \\
n=249 \\
(\%)\end{array}$ & $\begin{array}{c}(2) \\
40-49 \\
\mathrm{n}=444 \\
(\%)\end{array}$ & $\begin{array}{c}(3) \\
\mathbf{5 0 - 5 9} \\
\mathrm{n}=\mathbf{2 7 5} \\
(\%)\end{array}$ & $\begin{array}{c}\mathbf{P} \\
\text { Value }\end{array}$ & $\begin{array}{l}\text { PR } \\
\text { (2) vs. } \\
\text { (1) }\end{array}$ & $\begin{array}{c}P- \\
\text { value }\end{array}$ & $\begin{array}{l}\text { PR } \\
\text { (3) vs. } \\
\text { (1) }\end{array}$ & $\begin{array}{c}\text { P- } \\
\text { value }\end{array}$ \\
\hline Strongly/Somewhat disagree & $115(12)$ & $21(9)$ & $35(8)$ & $59(21)$ & & ref & & ref & \\
\hline Not applicable & $90(9)$ & $10(4)$ & $33(7)$ & $46(17)$ & & - & & - & \\
\hline $\begin{array}{l}\text { I'm afraid there is something } \\
\text { inside me that doesn't belong } \\
\text { there }\end{array}$ & & & & & $<0.001$ & & & & \\
\hline Strongly/Somewhat agree & $671(69)$ & $201(81)$ & $320(72)$ & $150(54)$ & & 0.89 & 0.271 & 0.71 & 0.072 \\
\hline Strongly/Somewhat disagree & $208(22)$ & $38(15)$ & $90(20)$ & $80(29)$ & & ref & & ref & \\
\hline Not applicable & $89(9)$ & $9(4)$ & $34(8)$ & $45(16)$ & & - & & - & \\
\hline $\begin{array}{l}\text { I'm afraid of other possible } \\
\text { health } \\
\text { complications }\end{array}$ & & & & & 0.001 & & & & \\
\hline Strongly/Somewhat agree & $610(63)$ & $184(74)$ & $288(65)$ & $139(51)$ & & 0.91 & 0.461 & 0.77 & 0.223 \\
\hline Strongly/Somewhat disagree & $251(26)$ & $53(21)$ & $111(25)$ & $87(32)$ & & ref & & ref & \\
\hline Not applicable & $106(11)$ & $13(5)$ & $45(10)$ & $49(18)$ & & - & & - & \\
\hline $\begin{array}{l}\text { I'm afraid I am going to need } \\
\text { a } \\
\text { hysterectomy }\end{array}$ & & & & & $<0.001$ & & & & \\
\hline Strongly/Somewhat agree & $535(55)$ & $161(65)$ & $263(59)$ & $111(40)$ & & 0.99 & 0.938 & 0.75 & 0.252 \\
\hline Strongly/Somewhat disagree & $317(33)$ & $73(29)$ & $129(29)$ & $114(42)$ & & ref & & ref & \\
\hline Not applicable & $116(12)$ & $14(6)$ & $51(12)$ & $50(18)$ & & - & & - & \\
\hline $\begin{array}{l}\text { I'm afraid that the fibroids } \\
\text { might } \\
\text { turn into cancer }\end{array}$ & & & & & $<0.001$ & & & & \\
\hline Strongly/Somewhat agree & $519(54)$ & $165(66)$ & $245(55)$ & $109(40)$ & & 0.87 & 0.403 & 0.73 & 0.257 \\
\hline Strongly/Somewhat disagree & $352(36)$ & $71(28)$ & $157(35)$ & $125(45)$ & & ref & & ref & \\
\hline Not applicable & $97(10)$ & $13(5)$ & $43(10)$ & $41(15)$ & & - & & - & \\
\hline $\begin{array}{l}\text { I'm afraid fibroids will affect } \\
\text { my sex } \\
\text { life }\end{array}$ & & & & & $<0.001$ & & & & \\
\hline Strongly/Somewhat agree & $502(52)$ & $163(65)$ & $245(55)$ & $94(34)$ & & 1.28 & 0.110 & 1.22 & 0.465 \\
\hline Strongly/Somewhat disagree & $304(31)$ & $67(27)$ & $127(29)$ & $110(40)$ & & ref & & ref & \\
\hline Not applicable & $162(17)$ & $19(8)$ & $72(16)$ & $72(26)$ & & - & & - & \\
\hline $\begin{array}{l}\text { I'm afraid fibroids will affect } \\
\text { my } \\
\text { relationship with my } \\
\text { husband/significant other }\end{array}$ & & & & & $<0.001$ & & & & \\
\hline Strongly/Somewhat agree & $391(40)$ & $122(49)$ & $199(45)$ & $70(26)$ & & 1.16 & 0.463 & 0.73 & 0.374 \\
\hline Strongly/Somewhat disagree & $375(39)$ & $102(41)$ & $150(34)$ & $123(45)$ & & ref & & ref & \\
\hline Not applicable & $202(12)$ & $26(10)$ & $95(21)$ & $82(30)$ & & - & & - & \\
\hline $\begin{array}{l}\text { I'm afraid my body will never } \\
\text { be } \\
\text { normal again }\end{array}$ & & & & & $<0.001$ & & & & \\
\hline Strongly/Somewhat agree & 449 (46) & $150(60)$ & $215(49)$ & $84(30)$ & & 0.96 & 0.848 & 0.75 & 0.372 \\
\hline Strongly/Somewhat disagree & $415(43)$ & $87(35)$ & $190(43)$ & $138(50)$ & & ref & & ref & \\
\hline Not applicable & $104(11)$ & $11(5)$ & $39(9)$ & $54(19)$ & & - & & - & \\
\hline $\begin{array}{l}\text { I'm afraid fibroids will affect } \\
\text { my }\end{array}$ & & & & & $<0.001$ & & & & \\
\hline
\end{tabular}

Am J Obstet Gynecol. Author manuscript; available in PMC 2014 October 01. 


\begin{tabular}{|c|c|c|c|c|c|c|c|c|c|}
\hline $\begin{array}{l}\text { Concerns regarding uterine } \\
\text { fibroids }\end{array}$ & $\begin{array}{c}\text { Overall } \\
\mathbf{n}=968 \\
(\%)\end{array}$ & $\begin{array}{c}(1) \\
29-39 \\
n=249 \\
(\%)\end{array}$ & $\begin{array}{c}(2) \\
40-49 \\
n=444 \\
(\%)\end{array}$ & $\begin{array}{c}(3) \\
50-59 \\
n=275 \\
(\%)\end{array}$ & $\begin{array}{c}\mathbf{P} \\
\text { Value }\end{array}$ & $\begin{array}{l}\text { PR } \\
\text { (2) vs. } \\
\text { (1) }\end{array}$ & $\begin{array}{c}P- \\
\text { value }\end{array}$ & $\begin{array}{l}\text { PR } \\
\text { (3) vs. } \\
\text { (1) }\end{array}$ & $\begin{array}{c}\text { P- } \\
\text { value }\end{array}$ \\
\hline \multicolumn{10}{|l|}{$\begin{array}{l}\text { ability to have a successful } \\
\text { and } \\
\text { healthy pregnancy }\end{array}$} \\
\hline Strongly/Somewhat agree & $242(25)$ & $123(49)$ & $97(22)$ & $21(8)$ & & 0.94 & 0.745 & 0.44 & 0.053 \\
\hline Strongly/Somewhat disagree & $253(26)$ & $58(23)$ & $111(25)$ & $83(30)$ & & ref & & ref & \\
\hline Not applicable & $474(49)$ & $68(27)$ & $235(53)$ & $171(62)$ & & - & & - & \\
\hline $\begin{array}{l}\text { I'm afraid fibroids will make } \\
\text { me } \\
\text { depressed }\end{array}$ & & & & & $<0.001$ & & & & \\
\hline Strongly/Somewhat agree & $364(38)$ & $131(53)$ & $170(38)$ & $63(23)$ & & 0.89 & 0.586 & 0.55 & 0.123 \\
\hline Strongly/Somewhat disagree & $466(48)$ & $100(40)$ & $211(48)$ & $155(56)$ & & ref & & ref & \\
\hline Not applicable & $138(14)$ & $18(7)$ & $63(14)$ & $57(21)$ & & - & & - & \\
\hline
\end{tabular}

Note: Data are weighted. Columns do not always sum to the total due to rounding.

PR = Prevalence Ratio (Adjusted for patient characteristics described in Table 1); ref = reference category

\section{Appendix Table 2}

\section{Employment Concerns}

\begin{tabular}{|c|c|c|c|c|c|c|c|c|c|}
\hline \multicolumn{10}{|c|}{ Age Categories } \\
\hline Employment concerns & $\begin{array}{c}\text { All } \\
\text { Participants } \\
\mathbf{n}=\mathbf{6 3 8}\end{array}$ & $\begin{array}{c}(1) \\
29-39 \\
n=183 \\
(\%)\end{array}$ & $\begin{array}{c}(2) \\
40-49 \\
\mathrm{n}=282 \\
(\%)\end{array}$ & $\begin{array}{c}(3) \\
\mathbf{5 0 - 5 9} \\
\mathbf{n}=173 \\
(\%)\end{array}$ & $\begin{array}{c}\mathbf{P} \\
\text { Value }\end{array}$ & $\begin{array}{l}\text { PR } \\
\text { (2) } \\
\text { vs. } \\
\text { (1) }\end{array}$ & $\begin{array}{c}\text { P- } \\
\text { value }\end{array}$ & $\begin{array}{l}\text { PR } \\
\text { (3) vs. } \\
\text { (1) }\end{array}$ & P-value \\
\hline $\begin{array}{l}\text { Prevented me from carrying } \\
\text { out } \\
\text { normal work-related or } \\
\text { professional responsibilities }\end{array}$ & & & & & $<0.001$ & & & & \\
\hline Strongly/Somewhat agree & $164(26)$ & $64(35)$ & $77(27)$ & $23(13)$ & & 0.97 & 0.845 & 1.05 & 0.833 \\
\hline Strongly/Somewhat disagree & $474(74)$ & $120(65)$ & $205(73)$ & $150(87)$ & & ref & & ref & \\
\hline $\begin{array}{l}\text { Prevented me from reaching } \\
\text { my } \\
\text { true potential at work or in } \\
\text { my } \\
\text { professional life }\end{array}$ & & & & & 0.03 & & & & \\
\hline Strongly/Somewhat agree & $152(24)$ & $59(32)$ & $68(24)$ & $25(15)$ & & 0.93 & 0.598 & 0.90 & 0.607 \\
\hline Strongly/Somewhat disagree & $486(76)$ & $124(68)$ & $214(76)$ & $147(85)$ & & ref & & ref & \\
\hline $\begin{array}{l}\text { Caused me to miss days of } \\
\text { work }\end{array}$ & & & & & 0.002 & & & & \\
\hline Strongly/Somewhat agree & $179(28)$ & $67(37)$ & $84(30)$ & $28(16)$ & & 0.97 & 0.798 & 1.01 & 0.970 \\
\hline Strongly/Somewhat disagree & $458(72)$ & $116(63)$ & $198(70)$ & $144(84)$ & & ref & & ref & \\
\hline $\begin{array}{l}\text { Made me afraid I'll lose my } \\
\text { job }\end{array}$ & & & & & $<0.001$ & & & & \\
\hline Strongly/Somewhat agree & $75(12)$ & $39(21)$ & $28(10)$ & $9(5)$ & & 1.15 & 0.098 & 1.22 & 0.127 \\
\hline Strongly/Somewhat disagree & $563(88)$ & $144(79)$ & $254(90)$ & $164(95)$ & & ref & & ref & \\
\hline $\begin{array}{l}\text { Prevented me from traveling } \\
\text { for }\end{array}$ & & & & & $<0.001$ & & & & \\
\hline Strongly/Somewhat agree & $93(15)$ & $36(19)$ & $44(15)$ & $14(8)$ & & 1.01 & 0.909 & 1.11 & 0.497 \\
\hline Strongly/Somewhat disagree & $545(85)$ & $148(81)$ & $238(85)$ & $159(92)$ & & ref & & ref & \\
\hline
\end{tabular}

Am J Obstet Gynecol. Author manuscript; available in PMC 2014 October 01. 


\begin{tabular}{|c|c|c|c|c|c|c|c|c|c|}
\hline \multicolumn{10}{|c|}{ Age Categories } \\
\hline Employment concerns & $\begin{array}{l}\text { All } \\
\text { Participants } \\
\mathbf{n = 6 3 8}\end{array}$ & $\begin{array}{c}(1) \\
29-39 \\
n=183 \\
(\%)\end{array}$ & $\begin{array}{c}(2) \\
40-49 \\
\mathrm{n}=282 \\
(\%)\end{array}$ & $\begin{array}{c}(3) \\
\mathbf{5 0 - 5 9} \\
\mathbf{n}=173 \\
(\%)\end{array}$ & $\begin{array}{c}\mathbf{P} \\
\text { Value }\end{array}$ & $\begin{array}{l}\text { PR } \\
(2) \\
\text { vs. } \\
(1)\end{array}$ & $\begin{array}{c}\text { P- } \\
\text { value }\end{array}$ & $\begin{array}{l}\text { PR } \\
\text { (3) vs. } \\
\text { (1) }\end{array}$ & P-value \\
\hline \multicolumn{10}{|l|}{$\begin{array}{l}\text { Treatment concerns related } \\
\text { to } \\
\text { work }\end{array}$} \\
\hline $\begin{array}{l}\text { Number of days missed from } \\
\text { work } \\
\text { for recovery }\end{array}$ & & & & & 0.29 & & & & \\
\hline Concerned & $421(66)$ & $121(66)$ & $195(69)$ & $105(61)$ & & 1.06 & 0.722 & 0.92 & 0.736 \\
\hline Not concerned & $195(31)$ & $60(33)$ & $74(26)$ & $61(35)$ & & ref & & ref & \\
\hline Not sure & $22(3)$ & $2(1)$ & $13(5)$ & $7(4)$ & & - & & - & \\
\hline Potential loss of income & & & & & 0.73 & & & & \\
\hline Concerned & $336(53)$ & $106(58)$ & $147(52)$ & $82(48)$ & & 0.97 & 0.867 & 1.06 & 0.874 \\
\hline Not concerned & $272(43)$ & $69(38)$ & $122(43)$ & $80(47)$ & & ref & & ref & \\
\hline Not sure & $30(5)$ & $7(4)$ & $13(5)$ & $10(6)$ & & - & & - & \\
\hline
\end{tabular}

Note: Data are weighted. Columns do not always sum to the total due to rounding.

P-values are from $X^{2}$ statistics comparing responses from women age 29-39, 40-49 and 40-59. P-values $<0.05$ are considered statistically significant.

\section{Appendix Table 3}

Text from the Email that was sent to potential survey respondents from Harris Poll Online: Subject: We need your opinion, please participate today!

[Start Survey] button

Hello, The latest Harris Poll Online survey is now open and we want your opinion! In order to receive the reward mentioned you will need to qualify and complete the survey. To participate, please click the "Start Survey" button above. If the button fails to launch the survey, please copy and paste the link below into the address bar of your browser.

For survey comments and concerns, contact the Survey Help Desk. You received this email because you are a member of the Harris Poll Online Panel. The Harris Poll Online Panel is a product of Harris Interactive, 60 Corporate Woods, Rochester, NY 14623-1457."

On the side of the Email: it noted that qualifying and completing the survey would reward the participant with up to 100 HI points and an entry into a $\$ 10,000$ sweepstakes. The length was 18 minutes, and a survey code. The bottom of the Email included a link to unsubscribe from the Harris Poll Online.

\section{References}

1. Day, Baird D.; Dunson, DB.; Hill, MC.; Cousins, D.; Schectman, JM. High cumulative incidence of uterine leiomyoma in black and white women: ultrasound evidence. American journal of obstetrics and gynecology. 2003; 188:100-107. [PubMed: 12548202]

2. Laughlin SK, Stewart EA. Uterine leiomyomas: individualizing the approach to a heterogeneous condition. Obstetrics and gynecology. 2011; 117:396-403. [PubMed: 21252757]

3. Carlson KJ, Nichols DH, Schiff I. Indications for hysterectomy. The New England journal of medicine. 1993; 328:856-860. [PubMed: 8357364]

4. Walker CL, Stewart EA. Uterine Fibroids: The Elephant in the Room. Science. 2005; 308:15891592. [PubMed: 15947177]

5. Marshall LM, Spiegelman D, Barbieri RL, et al. Variation in the incidence of uterine leiomyoma among premenopausal women by age and race. Obstetrics and gynecology. 1997; 90:967-973. [PubMed: 9397113] 
6. Zimmermann A, Bernuit D, Gerlinger C, Schaefers M, Geppert K. Prevalence, symptoms and management of uterine fibroids: an international internet-based survey of 21,746 women. BMC women's health. 2012; 12:16. [PubMed: 22727195]

7. Spies JB, Coyne K, Guaou Guaou N, Boyle D, Skyrnarz-Murphy K, Gonzalves SM. The UFS-QOL, a new disease-specific symptom and health-related quality of life questionnaire for leiomyomata. Obstetrics and gynecology. 2002; 99:290-300. [PubMed: 11814511]

8. Schonlau M, Zapert K, Simon LP, et al. A Comparison Between Responses From a PropensityWeighted Web Survey and an Identical RDD Survey. Social Science Computer Review. 2004; 22:128-138.

9. Terhanian G, Bremer J, Smith R, Thomas R. Correcting data from online surveys for the effects of nonrandom selection and nonrandom assignment.: HarrisInteractive. 2000; 2013

10. Rothman, KJ.; Greenland, S.; Lash, TL. Modern Epidemiology. Philadelphia, PA: Lippincott, Williams, \& Wilkins; Number of pages;

11. Deddens JA, Petersen MR. Approaches for estimating prevalence ratios. Occupational and environmental medicine. 2008; 65:481. 501-6. [PubMed: 18562687]

12. Zou G. A modified poisson regression approach to prospective studies with binary data. American journal of epidemiology. 2004; 159:702-706. [PubMed: 15033648]

13. Baird DD, Dunson DB, Hill MC, Cousins D, Schectman JM. High cumulative incidence of uterine leiomyoma in black and white women: ultrasound evidence. Am J Obstet Gynecol. 2003; 188:100-107. [PubMed: 12548202]

14. Cardozo ER, Clark AD, Banks NK, Henne MB, Stegmann BJ, Segars JH. The estimated annual cost of uterine leiomyomata in the United States. American journal of obstetrics and gynecology. 2012; 206:211. e1-9. [PubMed: 22244472]

15. Peddada SD, Laughlin SK, Miner K, et al. Growth of uterine leiomyomata among premenopausal black and white women. Proceedings of the National Academy of Sciences of the United States of America. 2008; 105:19887-19892. [PubMed: 19047643]

16. Lee DW, Ozminkowski RJ, Carls GS, Wang S, Gibson TB, Stewart EA. The direct and indirect cost burden of clinically significant and symptomatic uterine fibroids. Journal of occupational and environmental medicine / American College of Occupational and Environmental Medicine. 2007; 49:493-506. [PubMed: 17495692]

17. Hartmann KE, Birnbaum H, Ben-Hamadi R, et al. Annual costs associated with diagnosis of uterine leiomyomata. Obstetrics and gynecology. 2006; 108:930-937. [PubMed: 17012456]

18. Flynn M, Jamison M, Datta S, Myers E. Health care resource use for uterine fibroid tumors in the United States. Am J Obstet Gynecol. 2006; 195:955-964. [PubMed: 16723104]

19. Lee DW, Gibson TB, Carls GS, Ozminkowski RJ, Wang S, Stewart EA. Uterine fibroid treatment patterns in a population of insured women. Fertil Steril. 2009; 91:566-574. [PubMed: 18304543]

20. Wechter ME, Stewart EA, Myers ER, Kho RM, Wu JM. Leiomyoma-related hospitalization and surgery: prevalence and predicted growth based on population trends. American Journal of Obstetrics and Gynecology. 2011; 205:p492. e1-92.e5.

21. Rocca WA, Grossardt BR, Shuster LT, Stewart EA. Hysterectomy, Oophorectomy, Estrogen, and the Risk of Dementia. Neuro-degenerative diseases. 2012

22. ACOG, practice bulletin. Alternatives to hysterectomy in the management of leiomyomas. Obstet Gynecol. 2008; 112:387-400. [PubMed: 18669742]

23. Wise LA, Palmer JR, Harlow BL, et al. Reproductive factors, hormonal contraception, and risk of uterine leiomyomata in African-American women: a prospective study. American journal of epidemiology. 2004; 159:113-123. [PubMed: 14718211]

24. Wise LA, Palmer JR, Stewart EA, Rosenberg L. Age-specific incidence rates for self-reported uterine leiomyomata in the Black Women's Health Study. Obstetrics and gynecology. 2005; 105:563-568. [PubMed: 15738025]

25. Heiervang E, Goodman R. Advantages and limitations of web-based surveys: evidence from a child mental health survey. Social psychiatry and psychiatric epidemiology. 2011; 46:69-76. [PubMed: 19921078]

26. van Gelder MM, Bretveld RW, Roeleveld N. Web-based questionnaires: the future in epidemiology? American journal of epidemiology. 2010; 172:1292-1298. [PubMed: 20880962] 
27. Kaplan RM. Shared medical decision making. A new tool for preventive medicine. American journal of preventive medicine. 2004; 26:81-83. [PubMed: 14700716] 


\section{CLINICAL IMPLICATIONS}

- The findings of this study can inform qualitative research and systematic analysis of women's preferences for care.

- Such work can be used to develop clinical decision-making tools and to promote shared decision making about treatment between women and their providers.

- Trials should be large enough to provide direct evidence on the effects of nonsurgical and surgical treatments on patient-centered outcomes, including quality of life and physical functioning, and to permit analyses specific to women of childbearing age.

- Studies of the direct and indirect costs of leiomyomas are needed to better inform clinicians and third-party payers. 


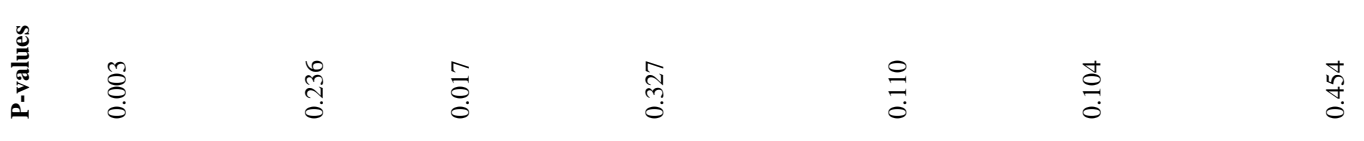

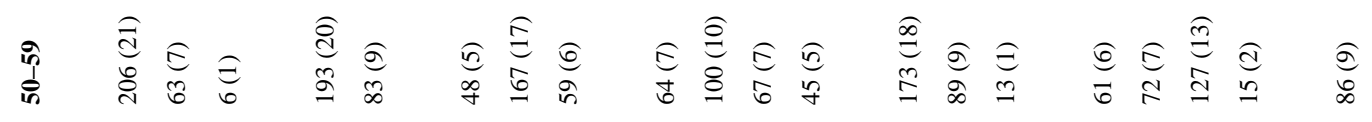

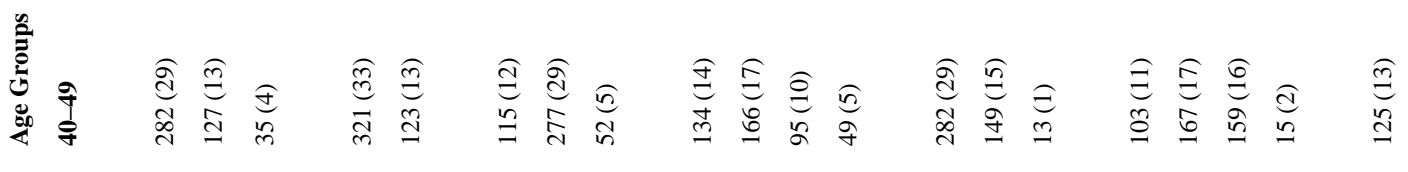

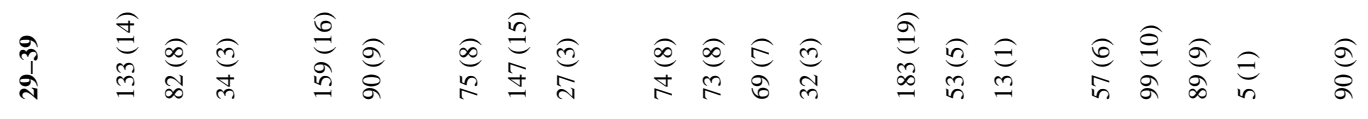

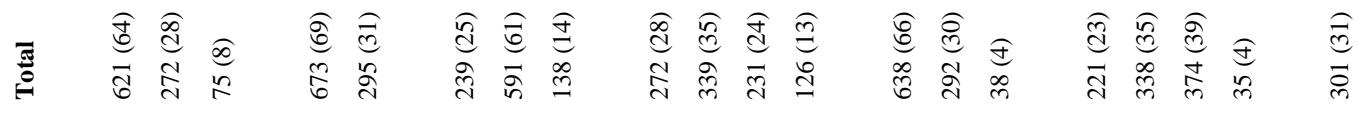




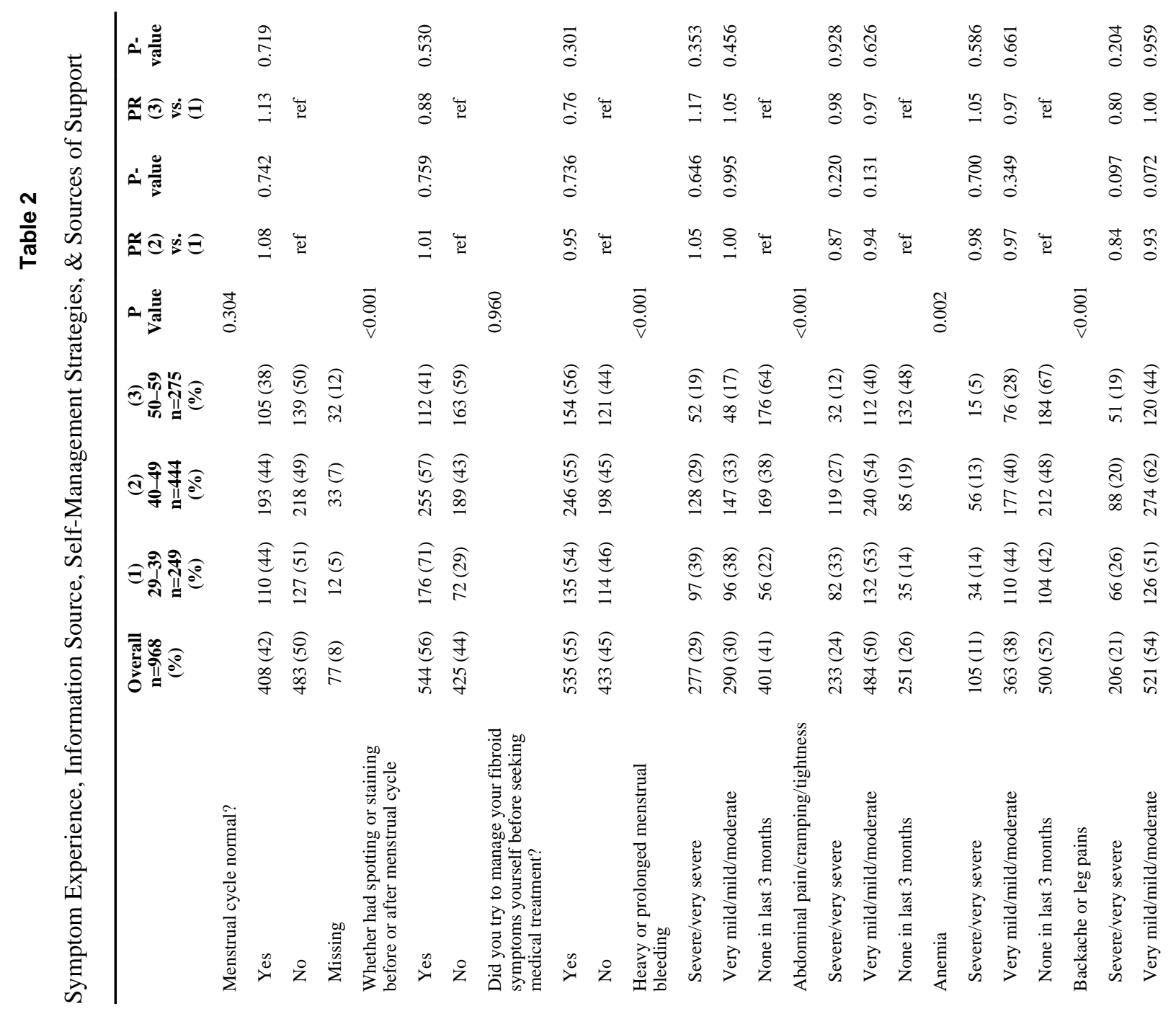




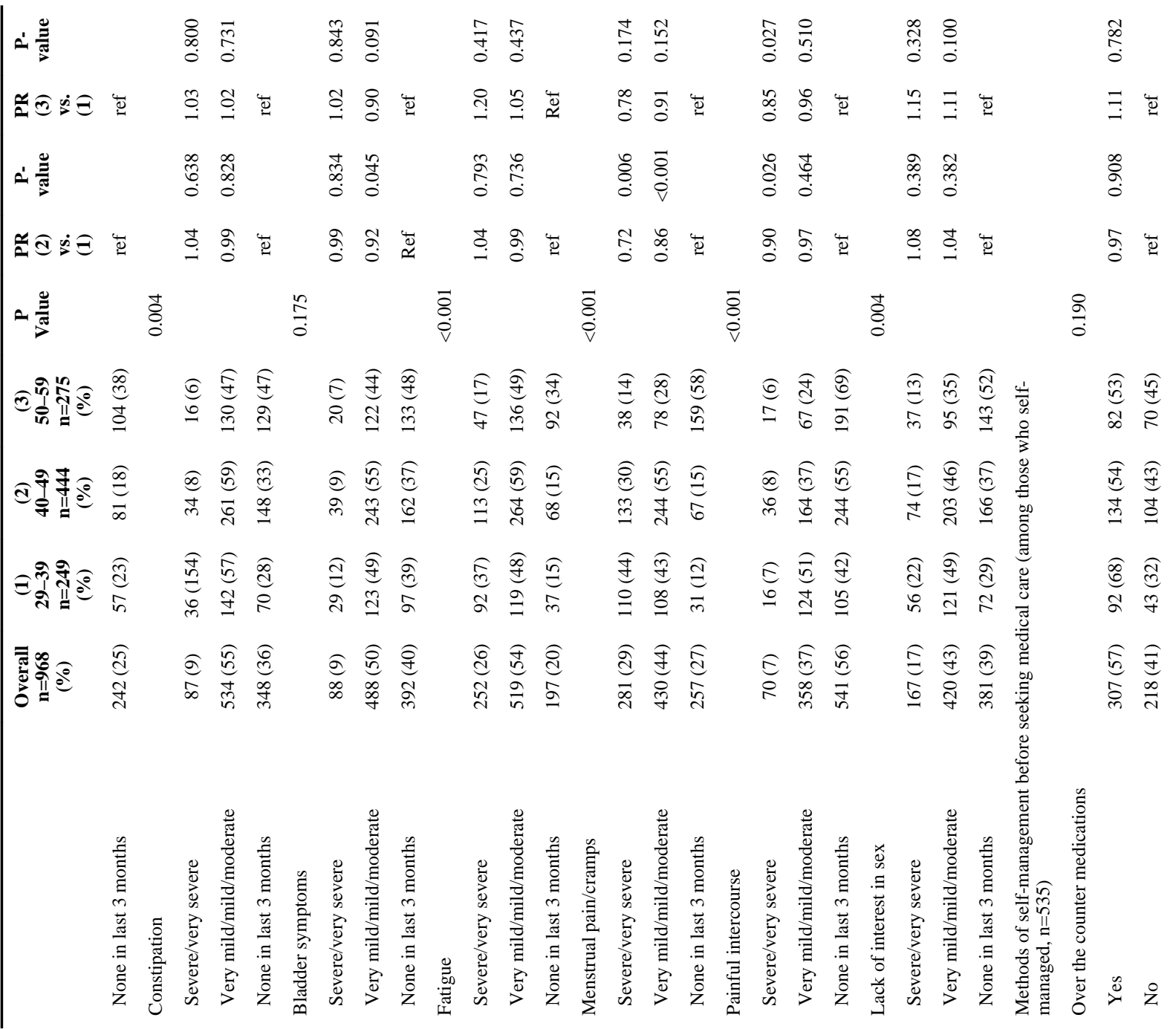




\begin{tabular}{|c|c|c|c|c|c|c|c|c|c|c|c|c|}
\hline & 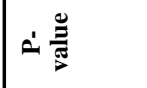 & 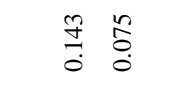 & & & 导是 & & $\begin{array}{l}\text { ڤे } \\
\infty \\
0 \\
0\end{array}$ & & $\begin{array}{c}0 \\
0 \\
0 \\
0\end{array}$ & & & $\begin{array}{ll}\bar{y} \\
0\end{array}$ \\
\hline & $\approx \underset{0}{2} \Theta$ & 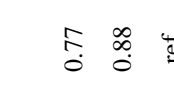 & 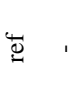 & & Oे & & $\stackrel{5}{a} \stackrel{\square}{-}$ & & 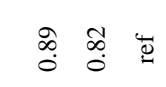 & ב. & & $\begin{array}{l}0 \\
0 \\
0\end{array}$ \\
\hline & 2 & 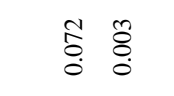 & & & 预 & & $\begin{array}{ll}n & n \\
i & 0 \\
0 & 0 \\
0\end{array}$ & & 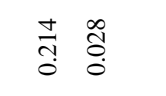 & & & वृ \\
\hline & 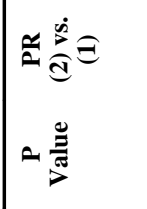 & 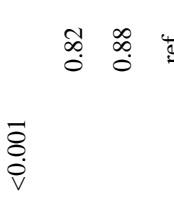 & Ф & $\bar{\delta}$ & 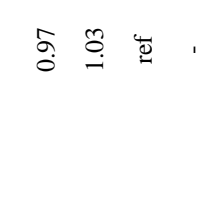 & $\overrightarrow{\bar{g}}$ & 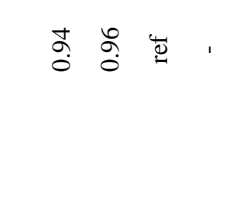 & $\overline{\bar{g}}$ & 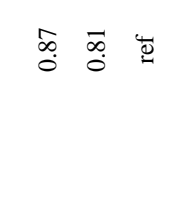 & . & $\begin{array}{l}\overline{8} \\
\dot{\nabla}\end{array}$ & \& \\
\hline & 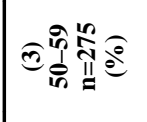 & 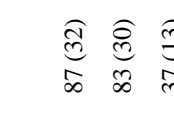 & 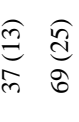 & & 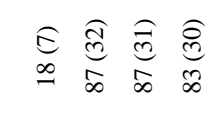 & & 产 & & 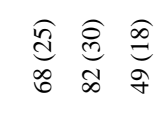 & : & & \\
\hline & 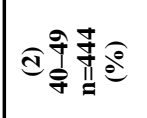 & 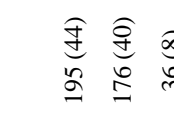 & $\begin{array}{ll}\infty & \\
\infty & \infty \\
c & \infty \\
\infty & \infty\end{array}$ & & 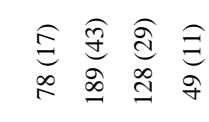 & Eे & 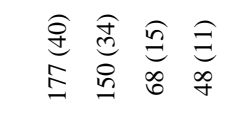 & & 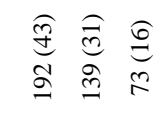 & $\frac{a}{a}$ & & \\
\hline 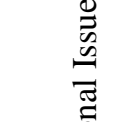 & 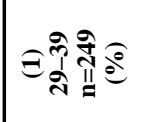 & 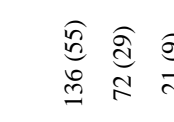 & $\begin{array}{ll}\hat{\sigma} & \widehat{\alpha} \\
\frac{\alpha}{a} & \end{array}$ & & 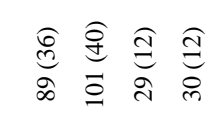 & $\begin{array}{l}\hat{E} \\
\text { E }\end{array}$ & 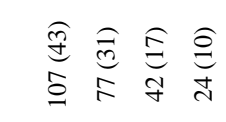 & & 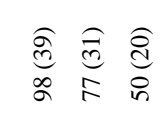 & $\frac{a}{d}$ & & $\stackrel{+}{\infty}$ \\
\hline 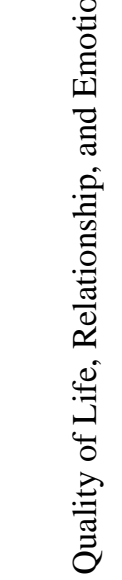 & 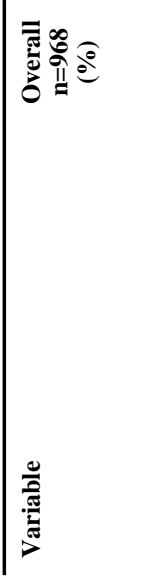 & 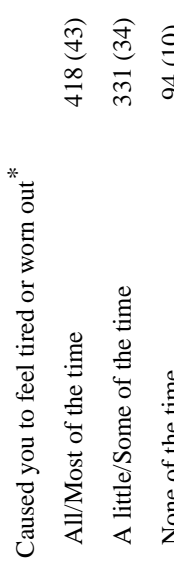 & 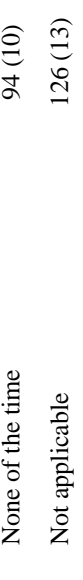 & 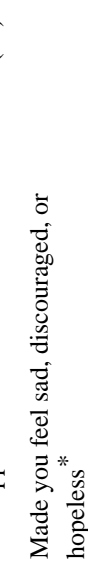 & 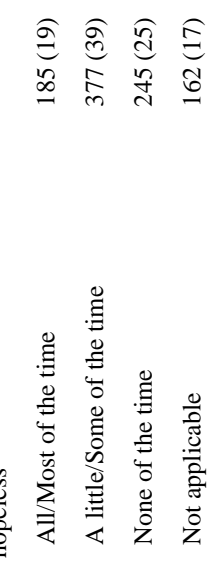 & 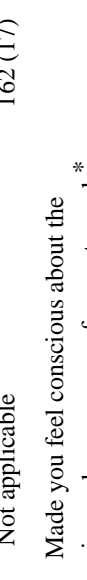 & 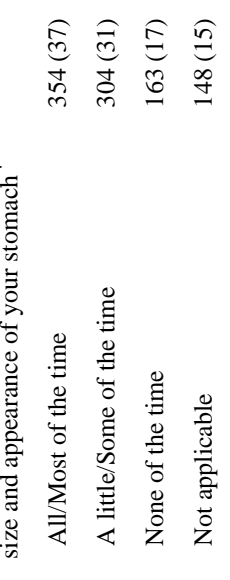 & 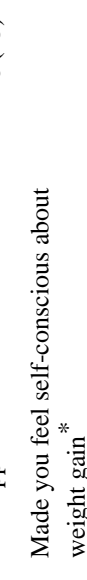 & 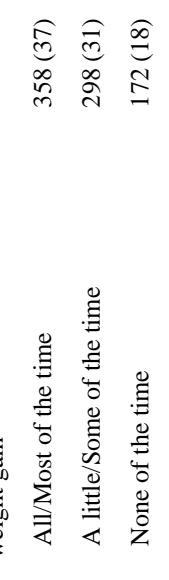 & 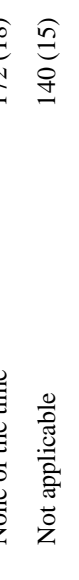 & 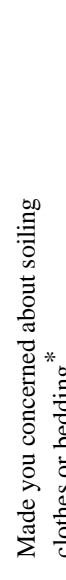 & 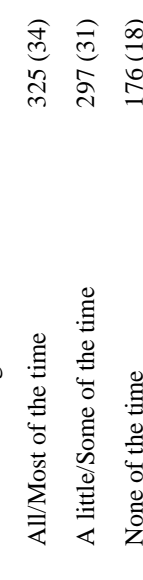 \\
\hline
\end{tabular}




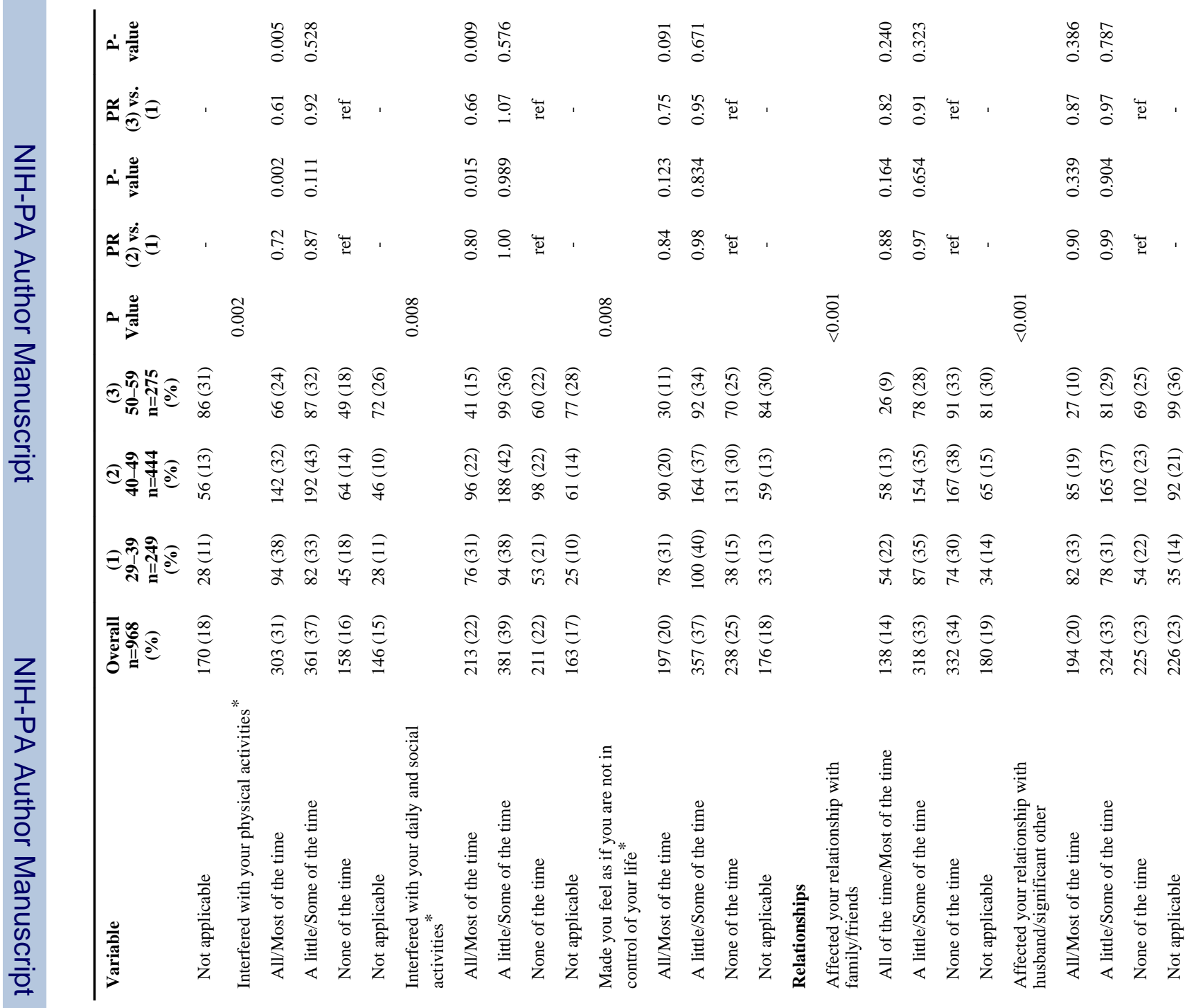




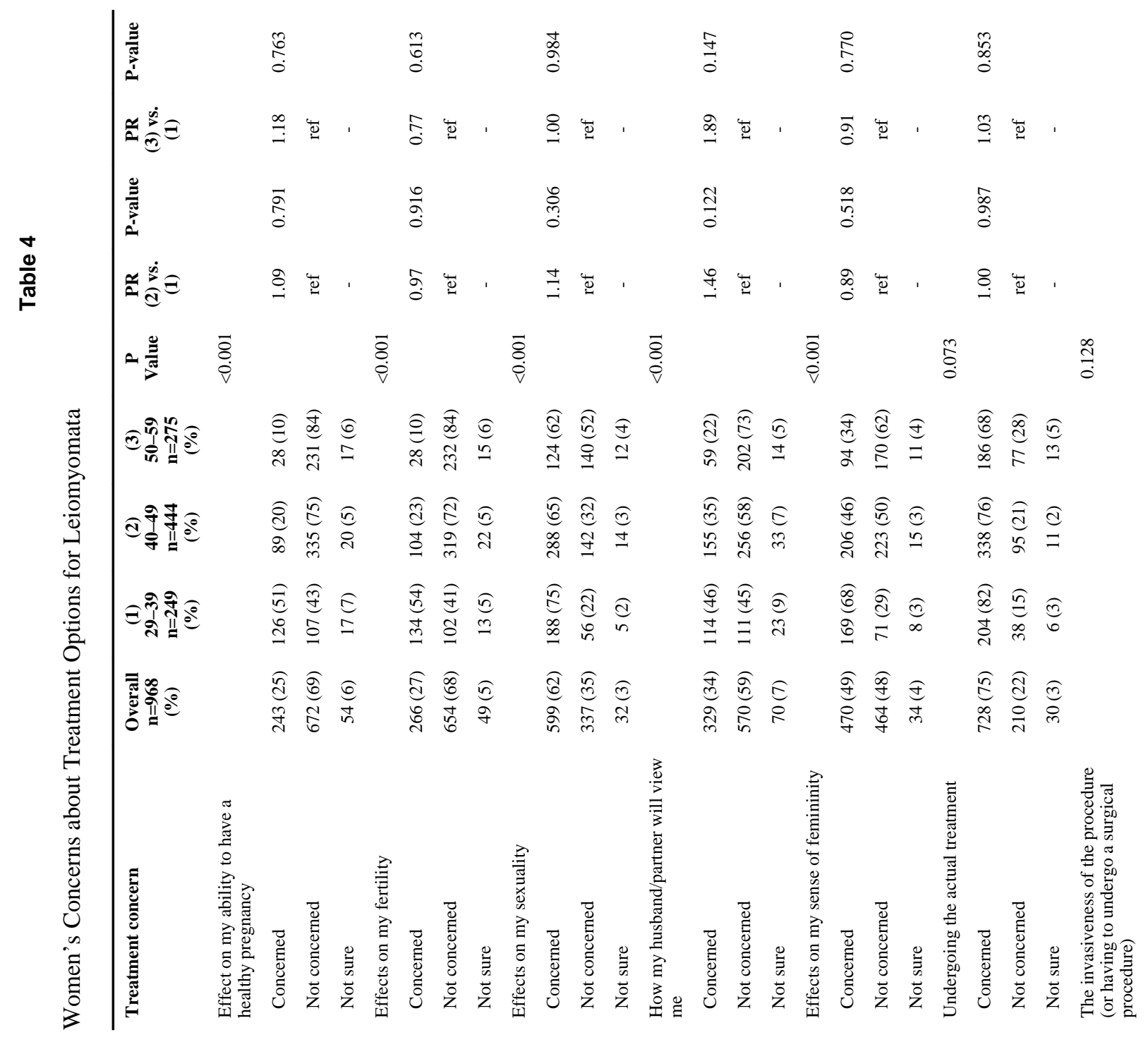




\begin{tabular}{|c|c|c|c|c|c|c|c|}
\hline 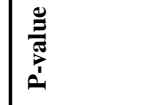 & 葡 & 突 & 导 & $\stackrel{q}{0}$ & م్ & 啇 & $\stackrel{n}{\frac{n}{0}}$ \\
\hline$\dot{0}$ & $\Xi \pm$ & Iี & $\stackrel{\infty}{\stackrel{\Xi}{0}}$ & $\stackrel{q}{g}$ & 志 & 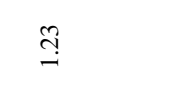 & $\stackrel{\overbrace{}}{\unlhd}$ \\
\hline . & $\frac{\infty}{3}$ & $\bar{n}$ & 号 & 㕝 & 旁 & $\begin{array}{l}n \\
\text { bे } \\
\text { o. }\end{array}$ & : \\
\hline$\frac{\dot{s}}{a} \in$ & $\stackrel{\infty}{=}$. & $\stackrel{\Xi}{\leftrightarrows}$ & $\bar{\sigma}_{\square}$ & త్తి ఫ్ & 吉 ఫ & $\stackrel{8}{-}$ & $\overline{\mathrm{g}} \mathrm{O}$ \\
\hline & $\stackrel{\infty}{0}$ & & $\overline{\mathrm{o}}$ & & & & \\
\hline 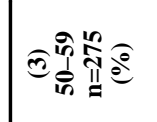 & 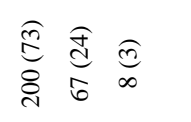 & 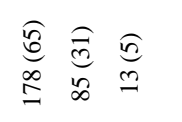 & 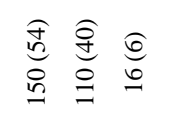 & 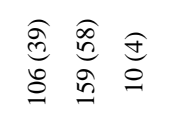 & $\begin{array}{l}\text { 恶点 } \\
\cong \\
\cong\end{array}$ & 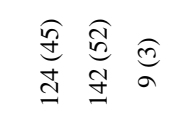 & $\begin{array}{ll}a & 0 \\
a & 0 \\
d & \delta\end{array}$ \\
\hline 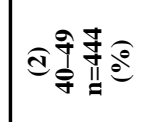 & 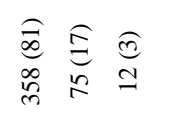 & 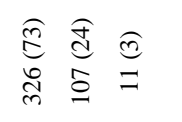 & 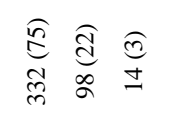 & 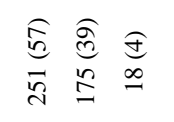 & 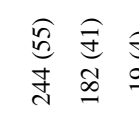 & 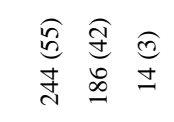 & 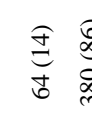 \\
\hline = & 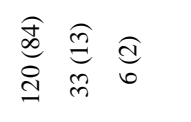 & 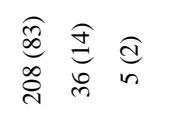 & 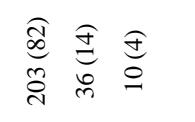 & 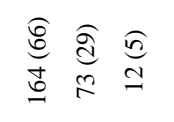 & 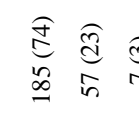 & 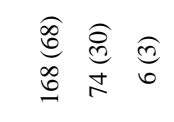 & 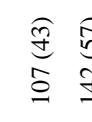 \\
\hline 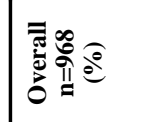 & 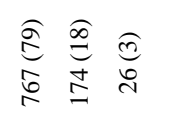 & 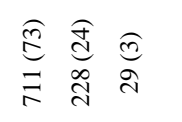 & 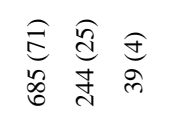 & 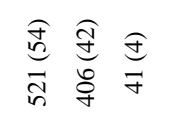 & 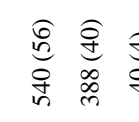 & 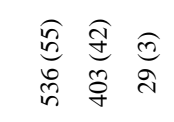 & 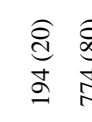 \\
\hline
\end{tabular}

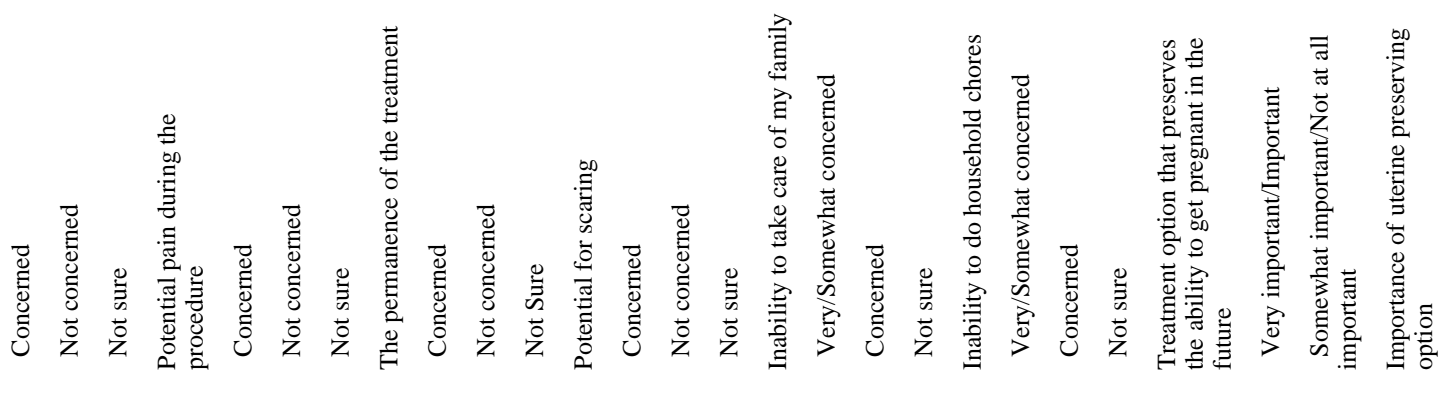




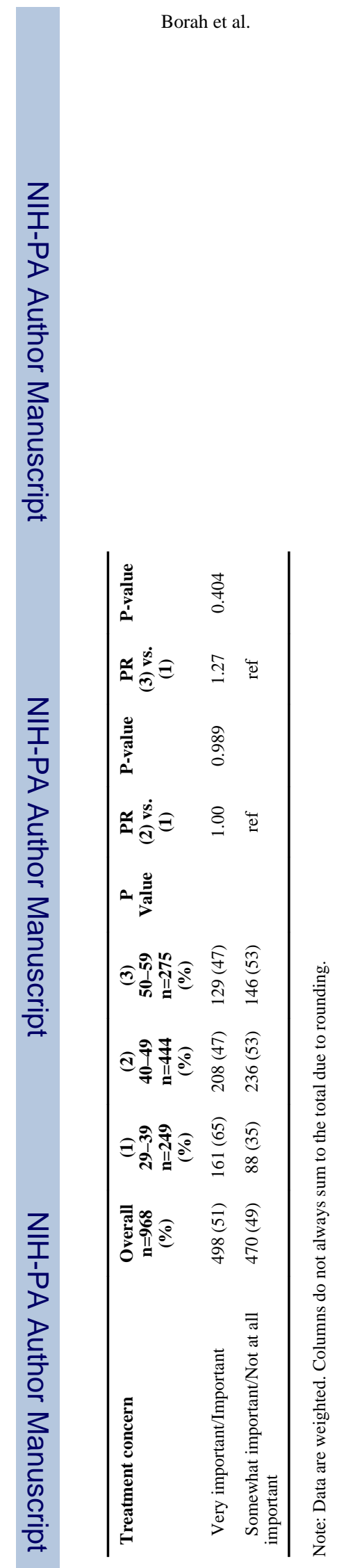

Am J Obstet Gynecol. Author manuscript; available in PMC 2014 October 01. 